\title{
GMR
}

\section{Mechanism of juglone-induced apoptosis of MCF-7 cells by the mitochondrial pathway}

\author{
Y.B. Ji, G.S. Xin, Z.Y. Qu, X. Zou and M. Yu \\ Center of Research and Development on Life Sciences and Environmental Sciences, \\ Harbin University of Commerce, Harbin, China \\ Corresponding author: Y. B. Ji \\ E-mail: 13766801150@163.com
}

Genet. Mol. Res. 15 (3): gmr.15038785

Received May 16, 2016

Accepted June 3, 2016

Published July 25, 2016

DOI http://dx.doi.org/10.4238/gmr.15038785

Copyright (C) 2016 The Authors. This is an open-access article distributed under the terms of the Creative Commons Attribution ShareAlike (CC BY-SA) 4.0 License.

\begin{abstract}
This study investigated the nature and mechanism of juglone-induced apoptosis in the human breast cancer cell line MCF-7. The inhibitory effect of juglone on MCF-7 cell growth was evaluated by the dimethylthiazol tetrazolium assay. Morphological apoptotic changes were characterized using an inverted microscope, Hoechst 33258 fluorescence staining, and Giemsa staining. The rate of cell apoptosis, intracellular levels of reactive oxygen species (ROS), and mitochondrial membrane potential were detected using flow cytometry. Intracellular $\mathrm{Ca}^{2+}$ concentrations were detected using laser scanning confocal fluorescence microscopy. Expression of the proteins Bcl-2, Bax, and cytochrome $\mathrm{C}$ was assessed by western blotting. Caspase-3 activity was quantified using a caspase-3 activity kit. Juglone inhibited the growth of MCF-7 cell line with an IC50 of $11.99 \mu \mathrm{M}$. The rates of MCF-7 cell apoptosis at $24 \mathrm{~h}$ after exposure to 5, 10, and $20 \mu \mathrm{M}$ juglone were $9.29,20.67$, and $28.39 \%$, respectively; compared to unexposed cells, juglone-exposed cells exhibited significant elevation in intracellular ROS level, decrease in mitochondrial membrane
\end{abstract}


potential, and increase in intracellular $\mathrm{Ca}^{2+}$ concentration. Juglone upregulated the expression of Bax, and downregulated the expression of Bcl-2, promoting the release of cytochrome $\mathrm{C}$, thereby upregulating the activity of caspase- 3 . The results suggest that the mechanism of juglone-induced apoptosis in MCF-7 cells is characterized by elevated ROS levels, reduced Bcl-2 expression, increased Bax expression, decreased mitochondrial membrane potential, increased intracellular $\mathrm{Ca}^{2+}$ concentration, outer mitochondrial-membrane rupture, cytochrome $\mathrm{C}$ release, and caspase- 3 activation.

Key words: Apoptosis; Intracellular $\mathrm{Ca}^{2+}$; Juglone; Mitochondrial membrane potential; Reactive oxygen species

\section{INTRODUCTION}

Breast cancer is the most common malignancy in women, and has become a substantial threat to women's health. The clinical treatment of breast cancer includes surgery and radiotherapy, both of which can cause significant physiological and psychological harm to patients. Heat therapy and Chinese medicine represent conservative treatment approaches that carry a lower risk of harm to patients, but are associated with reduced clinical effectiveness. Development of effective breast cancer treatments with low toxicity is thus a priority (Jaradat et al., 2016).

Juglone (5-hydroxy-1,4-naphthoquinone) has recently been shown to have strong antitumor activity (Kamei et al., 1998; Ji et al., 2011). Juglone was shown to exhibit strong anticancer activity against mouse ascites hepatoma, mouse S180 solid sarcoma, SGC-7901 human gastric cancer cells, HL-60 human leukemia cells, and HCT-15 human colon carcinoma cells (Segura-Aguilar et al., 1992; Kamei et al., 1998; Ji et al., 2011). The anticancer activity of juglone was found rely on the ability of the compound to kill tumor cells directly, induce apoptosis, inhibit the S-phase of the cell cycle, block the potassium channel (in human peripheral blood lymphocytes), inhibit the expression of the $p 53$ gene, and induce fast phosphorylation of histone H2AX. In other diseases, Juglone was found to be associated with production of reactive oxygen species (ROS) (Ji et al., 2011), and this may also be the case in various cancers.

Few data are available on the anticancer activity of juglone in human breast cancer cells. In order to add to the theoretical basis guiding the development of new drugs and their clinical application in the treatment of breast cancer, we studied the influence of juglone on the apoptosis of MCF-7 cells.

\section{MATERIAL AND METHODS}

\section{Reagents}

The following reagents were used in the experimental procedures: juglone with a purity of 97\% (Tianjin Yifang Ltd., China); hydroxycamptothecin (HCPT; Yellow Boulder Feiyun Pharmaceutical Co. Ltd., China); RPMI-1640 cell culture medium (Gibco, USA); 3-[4,5-dimethylthiazol-2-yl]-2,5 diphenyl tetrazolium bromide (MTT; Beijing Soledad Symbol

Genetics and Molecular Research 15 (3): gmr.15038785 
Technologies Ltd., China); $N$-acetyl-L-cysteine (NAC; Tianjin Yifang Ltd.); dimethyl sulfoxide (DMSO), trypsin, propidium iodide (PI; Sigma-Aldrich, USA); Fluo-3-acetoxymethyl ester (Fluo-3/AM; Molecular probe Co., USA); JC-1 mitochondrial membrane potential assay kit (Pik-Day Institute of Biotechnology, China); rhodamine 123 (Sigma-Aldrich); Giemsa stain (Ltd. Noble Ryder, China); mouse anti-human Bcl-2 antibody, mouse anti-human Bax antibody, mouse anti- $\beta$-actin antibody (Santa Cruz Biotechnology, USA); fluorescein isothiocyanate (FITC)-conjugated goat anti-mouse IgG antibody (Wuhan Boster Biological Engineering Co., Ltd., China); western blotting assay kit and cell immunoprecipitation lysates (Pik-Day Institute of Biotechnology); mouse anti-human cytochrome $\mathrm{C}$ antibody (Santa Cruz Biotechnology); caspase-3 activity assay kit (Beyotime Institute of Biotechnology, China); Ac-DEVD-pNA caspase-3 substrate (BioVision, USA).

\section{Instruments}

The following instruments and materials were used in the experimental procedures: CO-150-type $\mathrm{CO}_{2}$ cell culture incubator (NBS Co., USA), EPICS XL flow cytometer (Beckman Coulter Co., USA), CKX-41-32 inverted microscope (Olympus, Japan), fluorescence microscope (Leica, Germany), SW-CJ-2f super clean workbench (Suzhou Purification Plant, China), ELISA 680 microplate reader (Bio-Rad, USA), SP-2 confocal laser scanning microscope (Leica), 0.22-mm nitrocellulose membranes (Sigma-Aldrich), electrophoresis system (Bio-Rad, 165-8001), GIS-2019 gel imaging system (Tanon Science \& Technology Co., Ltd., China), automatic pipette (Gilson, France).

\section{Cell lines and culture conditions}

The MCF-7 cell line was provided by the Harbin University of Commerce (Harbin, China). Cells were cultured in RPMI-1640 medium supplemented with $10 \%$ fetal calf serum and maintained at $37^{\circ} \mathrm{C}$ in a $5 \% \mathrm{CO}_{2}$ atmosphere. The culture medium was changed every 2-3 days.

\section{Cell proliferation assay}

MCF-7 cells in the logarithmic growth phase were harvested by trypsin digestion. The resulting cell suspension was adjusted to a concentration of $1 \times 10^{4} / \mathrm{mL}$, and a $100-\mu \mathrm{L}$ aliquot was pipetted into each well of a 96-well culture plate. After culturing for $24 \mathrm{~h}, 100$ $\mu \mathrm{L}$ juglone solution with or without $10 \mathrm{mM}$ NAC was added to each well, to a final juglone concentration of $6.25,12.5,25$, or $50 \mathrm{M}$. HCPT $(40 \mu \mathrm{M})$ was added to each positive control well, and $100 \mu \mathrm{L}$ RPMI-1640 was added to each blank control well. After culturing for $72 \mathrm{~h}$ at $37^{\circ} \mathrm{C}$, the supernatant was removed, replaced with $100 \mu \mathrm{L} 0.5 \mathrm{mg} / \mathrm{mL}$ MTT; the plates were oscillated briefly and cultured for an additional $4 \mathrm{~h}$. The plates were then removed from the incubator, and MTT was replaced with $150 \mu \mathrm{L}$ DMSO; the plates were oscillated to dissolve the formazan, and the absorbance at $570 \mathrm{~nm}$ was read using an ELISA plate reader.

\section{Morphology of MCF-7 cells}

MCF-7 cells in logarithmic growth were harvested and, after adjusting to a concentration of $1 \times 10^{5} / \mathrm{mL}$, the suspensions were seeded into six-well culture plates. After

Genetics and Molecular Research 15 (3): gmr.15038785 
incubating for $24 \mathrm{~h}, 1 \mathrm{~mL}$ juglone solution with or without $10 \mathrm{mM}$ NAC was added to a final juglone concentration of 5,10 , or $20 \mu \mathrm{M}$. HCPT $(40 \mu \mathrm{M})$ in $1 \mathrm{~mL}$ RPMI-1640 was added to wells assigned to the control group. After culturing for $24 \mathrm{~h}$, cell morphology was evaluated using an inverted microscope.

\section{Giemsa staining}

The cell samples used for evaluation of morphology were fixed in paraformaldehyde at $4{ }^{\circ} \mathrm{C}$, washed with phosphate-buffered saline (PBS), and incubated at room temperature for $30 \mathrm{~min}$ in the dark with $1 \mathrm{~mL}$ Giemsa stain. After washing twice with PBS, the cells were observed using an inverted microscope.

\section{Fluorescence microscopy}

The cell samples used for evaluation of morphology were fixed in methanol and glacial acetic acid at $4^{\circ} \mathrm{C}$ for $1 \mathrm{~h}$ and washed with PBS. The cells were then incubated for $30 \mathrm{~min}$ in the dark at $37^{\circ} \mathrm{C}$ in a water bath with $1 \mathrm{~mL}$ Hoechst 33258 nucleic acid stain, and prepared for observation by fluorescence microscopy.

\section{Flow cytometric assay of cells undergoing apoptosis}

MCF-7 cells in logarithmic growth phase were plated at $1 \mathrm{~mL} /$ well in six-well plates. After culturing for $24 \mathrm{~h}, 1 \mathrm{~mL}$ juglone was added to each well to a final concentration of 5 , 10 , or $20 \mu \mathrm{M}$; HCPT $(1 \mathrm{~mL})$ was added to a final concentration of $40 \mu \mathrm{M}$. The same volume of RPMI-1640 was added to the control wells. The plates were incubated for $24 \mathrm{~h}$; cells were harvested, washed with PBS, and adjusted to a final concentration of $1 \times 10^{5} / \mathrm{mL}$. The cell suspensions were centrifuged for $5 \mathrm{~min}$ at $2000 \mathrm{~g}$, and the supernatants were discarded. The cells were washed three times with PBS, fixed in ice-cold ethanol (70\%), and kept overnight at $-20^{\circ} \mathrm{C}$. After washing three times with PBS, PI dye solution was added, and the cells were kept at $4{ }^{\circ} \mathrm{C}$ in the dark for $30 \mathrm{~min}$. After collection on $300-\mathrm{mm}$ mesh filters, the cell suspensions were assayed by flow cytometry.

\section{Detection of ROS levels}

Cells were harvested, suspended in RPMI-1640 containing dichloro-dihydrofluorescein diacetate (DCFH-DA, 1:1000) to a final concentration of $10 \mu \mathrm{M}$. The cell suspensions containing diluted DCFH-DA were incubated at $37^{\circ} \mathrm{C}$ in a water bath in the dark for $20 \mathrm{~min}$, and then washed three times with serum-free RPMI-1640. After collection on 300$\mathrm{mm}$ mesh filters, ROS levels were assayed by flow cytometry.

\section{Mitochondrial membrane assay}

After treating the cells with 5,10 , or $20 \mu \mathrm{M}$ juglone, HCPT $(40 \mu \mathrm{M})$ or RPMI1640 was added. After $24 \mathrm{~h}$, cells were harvested, resuspended in $500 \mu \mathrm{L}$ PBS plus $500 \mu \mathrm{L}$ rhodamine $123(20 \mathrm{mg} / \mathrm{mL})$, to a final concentration of $10 \mathrm{mg} / \mathrm{mL}$ rhodamine 123 , and kept for $30 \mathrm{~min}$ in the dark. The cells were collected after centrifugation at $2000 \mathrm{rpm}$ for $5 \mathrm{~min}$, washed 
once with PBS, and then resuspended in $800 \mu \mathrm{L}$ PBS. After collection on 300-mm mesh filters, the mitochondrial membranes were assayed by flow cytometry.

\section{Intracellular $\mathrm{Ca}^{2+}$ concentration}

Cells were cultured for $24 \mathrm{~h}$, collected, and resuspended in $500 \mu \mathrm{L}$ aliquots of PBS. A $200-\mu \mathrm{L}$ volume of Fluo-3/AM $(4 \mathrm{mg} / \mathrm{mL})$ was added, followed by incubation at $37^{\circ} \mathrm{C}$ in a water bath for $30 \mathrm{~min}$ in the dark. Fluo-3/AM was then removed by centrifugation at 2000g; the cells were washed once in PBS, and resuspended in $400 \mu \mathrm{L}$ PBS for observation by laser confocal microscopy to detect $\mathrm{Ca}^{2+}$ concentration.

\section{Caspase-3 activity assay}

The cells were treated with 5,10, or $20 \mathrm{mM}$ juglone solution, with or without $10 \mathrm{mM}$ NAC, and with HCPT (60 mM) or RPMI-1640, and incubated for $24 \mathrm{~h}$. Lysates of $2 \times 10^{6}$ cells each were prepared by incubation with $100 \mathrm{~mL}$ lysis buffer for $15 \mathrm{~min}$ on ice, centrifuged at $20,000 \mathrm{~g}$ for $15 \mathrm{~min}$ at $4^{\circ} \mathrm{C}$, and then collected in ice-cold centrifuge tubes. A blank solution containing $90 \mathrm{~mL}$ reaction buffer plus $10 \mathrm{~mL}$ Ac-DEVD-pNA and test solutions including a $10 \mathrm{~mL}$ sample from each group, $80 \mathrm{~mL}$ reaction buffer, and $10 \mathrm{~mL}$ Ac-DEVD-pNA, were incubated in 96 -well plates for $2 \mathrm{~h}$ at $37^{\circ} \mathrm{C}$. Caspase- 3 activity was measured at $405 \mathrm{~nm}$ using a microplate reader.

\section{Western blot assay of Bcl-2 and Bax expression}

The western blot assay was conducted as follows. Briefly, cells were treated and harvested, transferred to $1.5-\mathrm{mL}$ tubes, centrifuged at 20,000 $\mathrm{g}$, and washed twice with PBS. A $100-\mathrm{mL}$ volume of ice-cold cell-lysis buffer was added to the sample over $30 \mathrm{~min}$ in an ice water bath. Lysates were centrifuged at $25,600 \mathrm{~g}$ for $10 \mathrm{~min}$ at $4^{\circ} \mathrm{C}$. The supernatants were collected and stored at $-20^{\circ} \mathrm{C}$ until assayed. Electrophoresis was carried out on a mini-Protean 3 system (Bio-Rad).

\section{Flow cytometric assay of cytochrome $\mathrm{C}$ protein in MCF-7 cells}

Cells were treated and collected as described above, fixed in $4 \%(\mathrm{w} / \mathrm{v})$ paraformaldehyde for $40 \mathrm{~min}$, centrifuged 20,000 $\mathrm{g}$, and rinsed twice with PBS. After permeabilization with $2 \mathrm{~mL}$ $0.1 \%$ Triton X-100 for $15 \mathrm{~min}$, the samples were centrifuged at 20,000 $\mathrm{g}$ and rinsed twice with PBS. A $1-\mathrm{mL}$ volume of $1 \% \mathrm{BSA}$ was added to the centrifuge tubes, and, after $1 \mathrm{~h}$, the samples were centrifuged at 20,000 $\mathrm{g}$ and the supernatant was discarded. Mouse anti-cytochrome $\mathrm{C}$ antibody (1:200) was added, and, following $1 \mathrm{~h}$ incubation at $37^{\circ} \mathrm{C}$, the cells were washed with PBS. FITCconjugated goat anti-mouse IgG antibody (1:50) was added. After 30 min in the dark at ambient temperature, the cells were washed and re-suspended in $800 \mu \mathrm{L}$ PBS. After collection on 300-mm mesh filters, the cells were assayed by flow cytometry. Each experiment was repeated three times.

\section{Statistical analysis}

Data are reported as means \pm standard deviation. The groups of cells were compared

Genetics and Molecular Research 15 (3): gmr.15038785 
by one-way analysis of variance, followed by the Fisher F test. The significance of betweengroup differences was determined by the Student unpaired-sample $t$-test. Values of $\mathrm{P} \leq 0.05$ were considered significant.

\section{RESULTS}

\section{Juglone-inhibited proliferation of MCF-7 cells}

Inhibition of MCF-7 cell proliferation increased with juglone concentration, and the inhibition was stronger in the presence of juglone alone than in the presence of both juglone and NAC (Figure 1). Juglone inhibited MCF-7 cell proliferation with an IC50 of $11.99 \mu \mathrm{M}$; in the presence of NAC, the IC50 of juglone-induced inhibition was $49.75 \mu \mathrm{M}$.

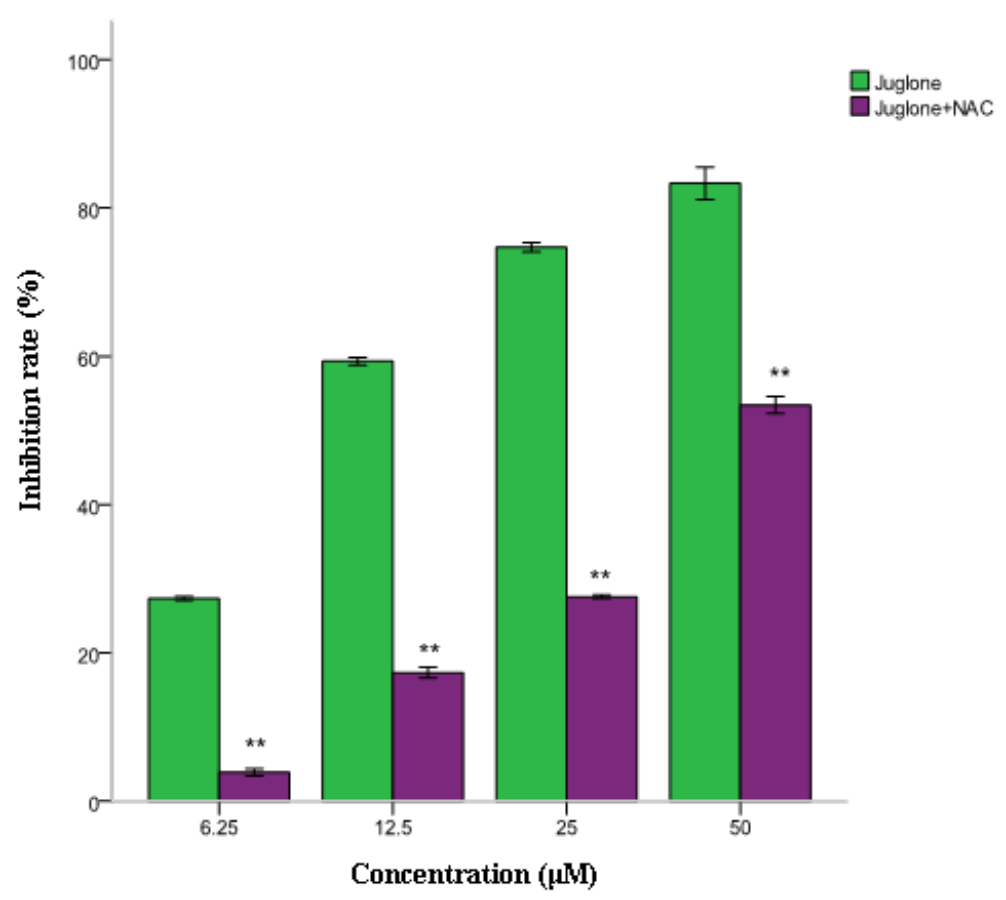

Figure 1. Juglone-induced inhibition of MCF-7 cell proliferation, in the presence or absence of NAC. Green = juglone group; purple $=$ juglone $+\mathrm{NAC}$ group; $\mathrm{X}$-axis $=$ juglone concentration; Y-axis $=$ inhibition rate. $* *$ Compared with juglone group $(\mathrm{P}<0.01)$. In both groups, the rate of apoptosis increases with juglone concentration. Apoptosis is more pronounced in the juglone group.

\section{Juglone-induced morphological changes of MCF-7 cells}

Examination using the inverted microscope revealed that the cells in the control group had grown adherently to the plate, and had intact cell membranes. In the juglone group, the density of plate-adherent cells decreased with increasing juglone concentration, and the cell membrane appeared wrinkled. Most cells in the high juglone-concentration group appeared collapsed, with incomplete cell morphology. In the juglone+NAC group, juglone-induced 
inhibition of MCF-7 cells was significantly lower than in the juglone group, irrespective of juglone concentration (Figure 2).

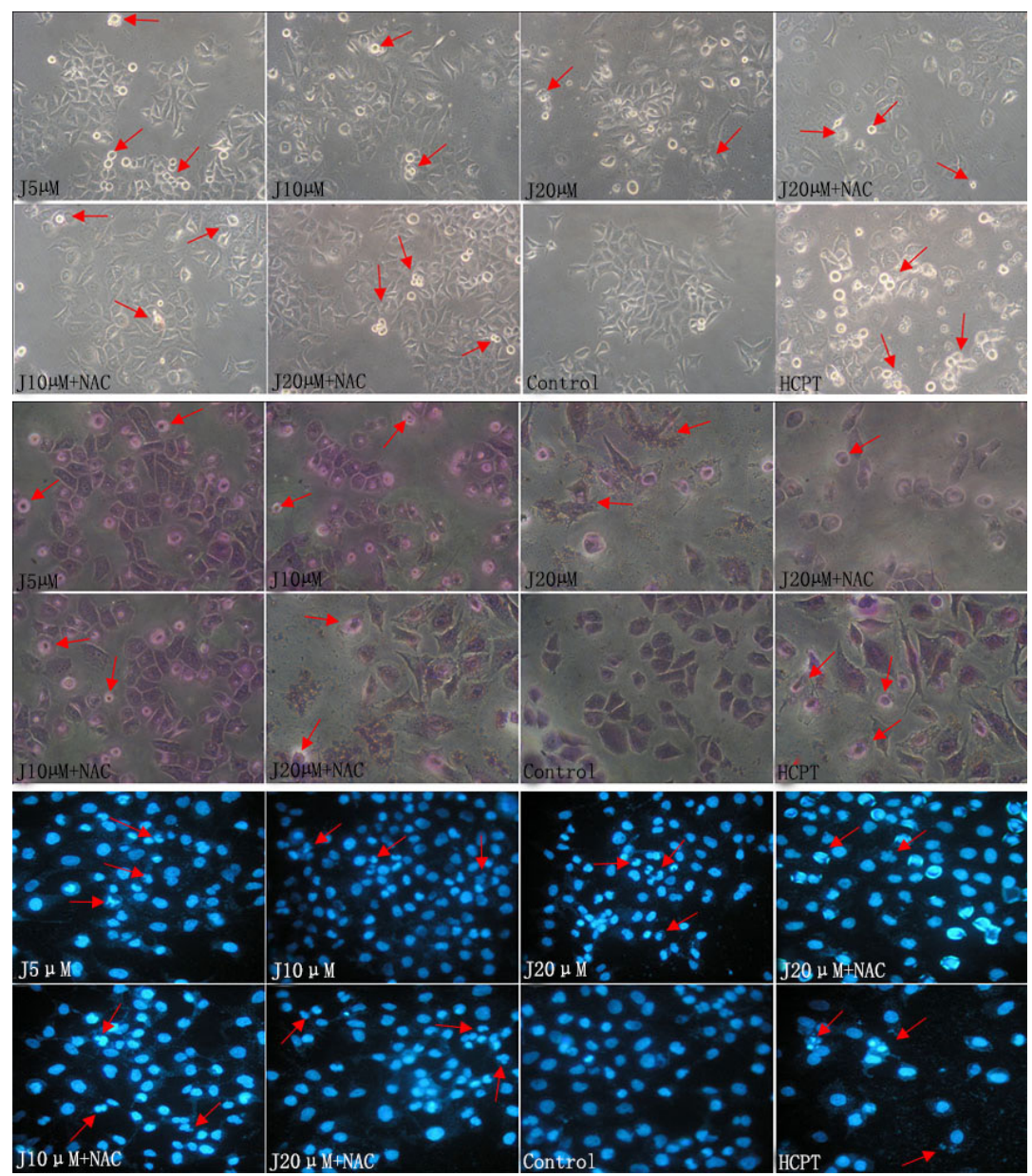

Figure 2. Morphological changes in MCF-7 cells at $24 \mathrm{~h}$ after juglone exposure. Top = inverted microscope images; middle $=$ Giemsa staining images; bottom $=$ fluorescence microscope images. Apoptosis-specific morphological changes were observed in all cases (red arrows), with higher incidence in the juglone and juglone+NAC groups than in the control group, and highest incidence in the HCPT group. The number of apoptotic cells increased with juglone concentration. This was also observed in the juglone+NAC group, but to a lesser extent than in the juglone group with the corresponding juglone concentration. Scale bar: $50 \mu \mathrm{m}$.

\section{Juglone-induced apoptosis of MCF-7 cells}

As shown in Figure 3, the apoptosis rate in positive controls was $30.26 \pm 0.07 \%$. The apoptosis rates increased with juglone concentration, from $9.29 \pm 0.09 \%$ at $5 \mu \mathrm{M}$, to $20.67 \pm$ $0.16 \%$ at $10 \mu \mathrm{M}$, and $28.39 \pm 0.37 \%$ at $20 \mu \mathrm{M}$. In the presence of NAC, the apoptosis rate for each juglone concentration was significantly decreased: $5.60 \pm 0.37 \%$ at $5 \mu \mathrm{M}, 11.35 \pm 0.59 \%$ at $10 \mu \mathrm{M}$, and $21.85 \pm 0.32 \%$ at $20 \mu \mathrm{M}$ (all with $\mathrm{P}<0.01$ ). 
A
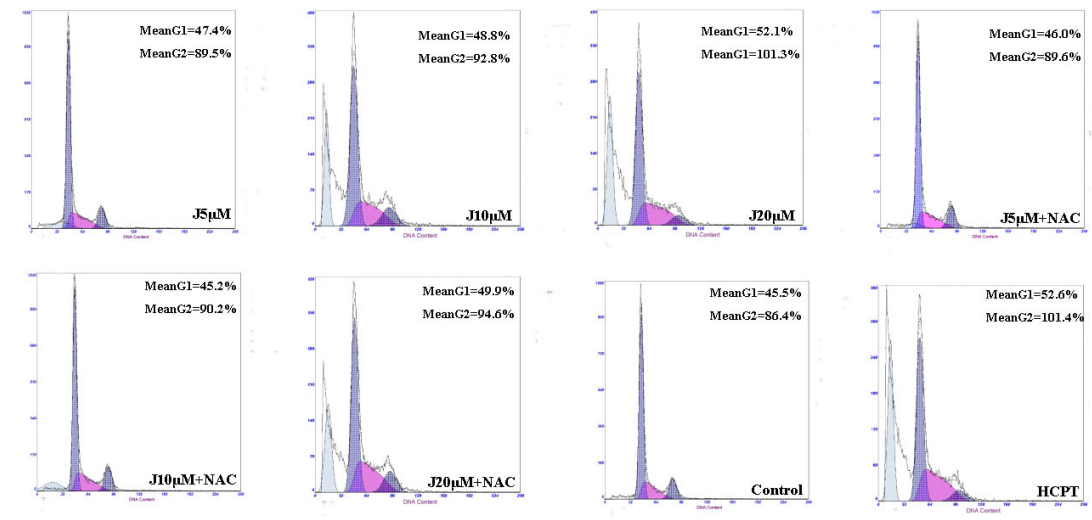

B

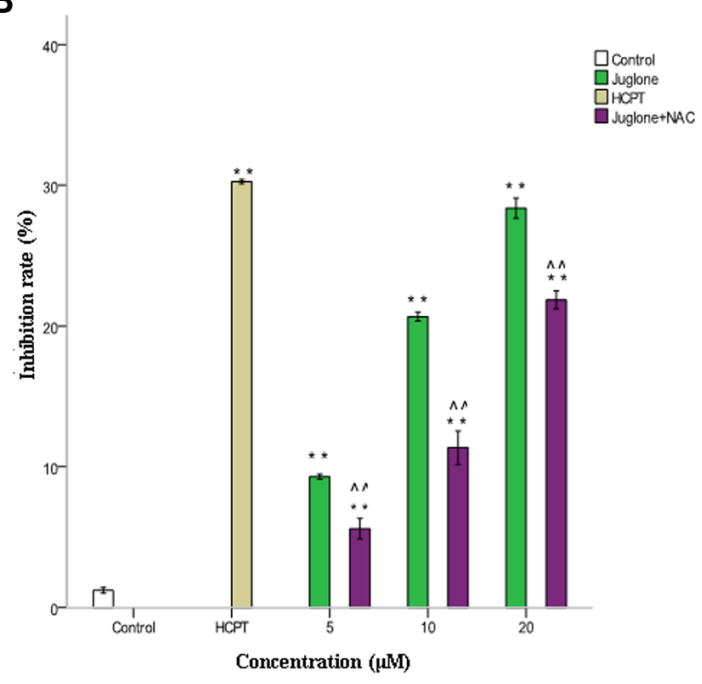

Figure 3. Flow cytometry results (A) and statistical analysis (B) of juglone-induced apoptosis of MCF-7 cells (72 h). The apoptosis rates in the juglone group were lower than those in the HCPT group $(\mathrm{H})$, and higher than those in the control and juglone+NAC group. Moreover, apoptosis rate increased with juglone concentration, and was higher than that in the juglone+NAC group for the same juglone concentration. **Comparison between assays with matching juglone concentrations $(\mathrm{P}<0.01)$.

\section{Effect of juglone on ROS levels in MCF-7 cells}

As shown in Figure 4, the ROS level in negative controls was $22.68 \pm 0.17 \%$, and $95.34 \pm 0.21 \%$ in positive controls. ROS levels in juglone-treated cells were $50.46 \pm 0.39 \%$ at $5 \mu \mathrm{M}, 60.34 \pm 0.26 \%$ at $10 \mu \mathrm{M}$, and $95.47 \pm 0.49 \%$ at $5 \mu \mathrm{M}$. Differences between the juglone and control groups were significant $(\mathrm{P}<0.01)$. ROS levels in cells treated with both juglone and NAC were $30.76 \pm 0.23 \%, 32.79 \pm 0.11 \%$, and $40.56 \pm 0.21 \%$ respectively, and were not significantly different from control rates $(\mathrm{P}<0.01)$. The presence of NAC significantly reduced ROS levels for each of the tested juglone concentrations $(\mathrm{P}<0.01)$. 


\section{A}
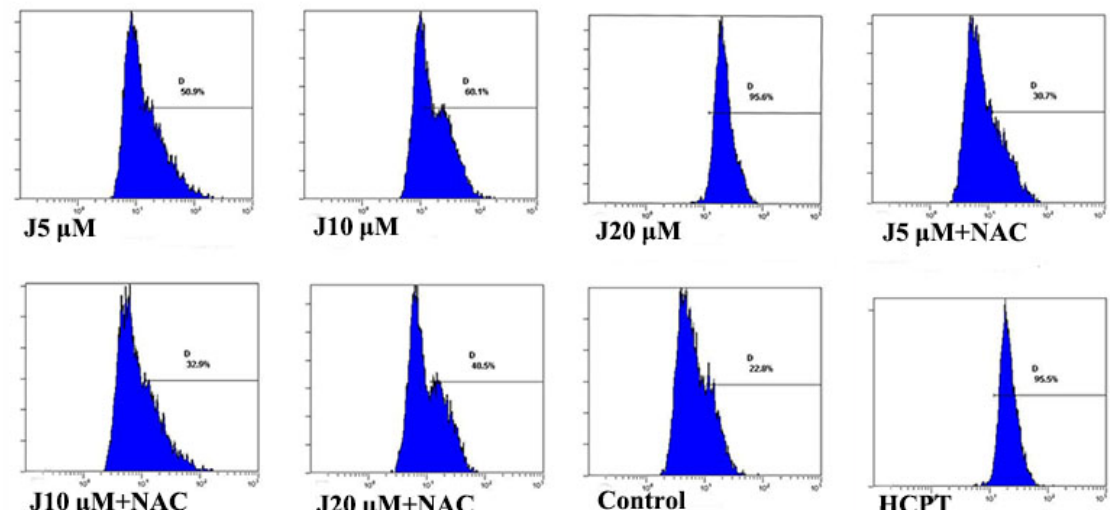

B

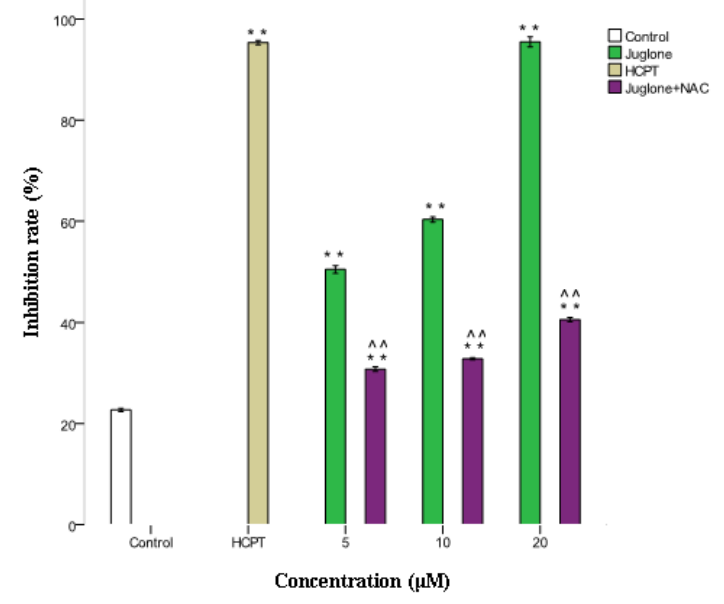

Figure 4. Flow cytometry and statistical analysis of the effect of juglone on ROS levels in MCF-7 cells. The green column represents the juglone group, the purple column represents juglone+NAC group, the X-axis represents the concentration and the Y-axis represents ROS level. ROS level in all juglone alone group and juglone+NAC group was higher than control group and lower than HCPT group. With the concentration increased, the ROS level increased gradually in both group, while that of juglone alone group was higher than juglone combined NAC group. ${ }^{* *}$ Comparison against control $(\mathrm{P}<0.01) .{ }^{\wedge}$ Compared with matched doses of juglone $\mathrm{P}<0.01$.

\section{Juglone effect on mitochondrial membrane potential}

As shown in Figure 5, cell mitochondrial membrane potential in blank controls was $86.62 \pm 0.10$ and $61.84 \pm 0.96 \%$ in positive controls. In juglone-treated cells, the mitochondrial membrane potentials were $74.26 \pm 0.12 \%$ at $5 \mu \mathrm{M}, 57.44 \pm 0.21 \%$ at $10 \mu \mathrm{M}$, and $47.33 \pm$ $0.16 \%$ at $20 \mu \mathrm{M}$, all of which were significantly lower that the blank control value $(\mathrm{P}<0.01)$. In the NAC combined treatment group, the mitochondrial membrane potentials were $82.65 \pm$ $0.28,67.35 \pm 0.21,54.50 \pm 0.33 \%$ respectively, and were significantly lower than the blank control and significantly higher than the corresponding juglone-only values (all $\mathrm{P}<0.01$ ). 
A
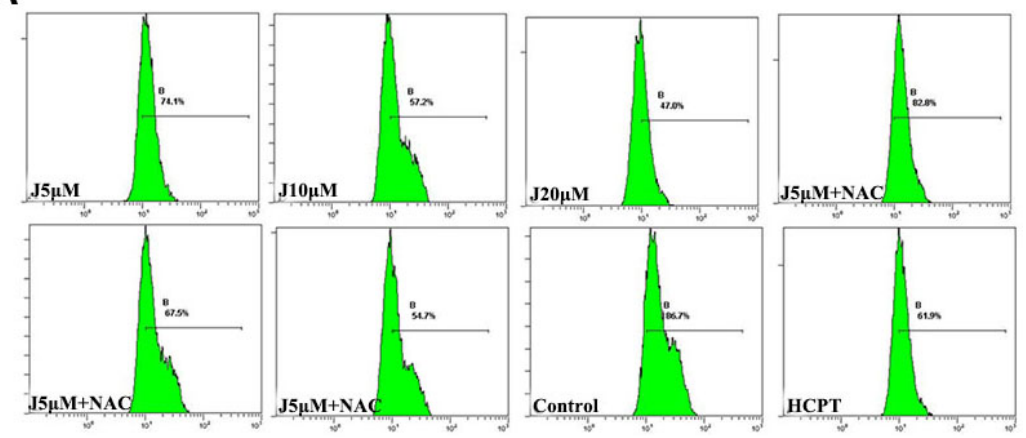

B

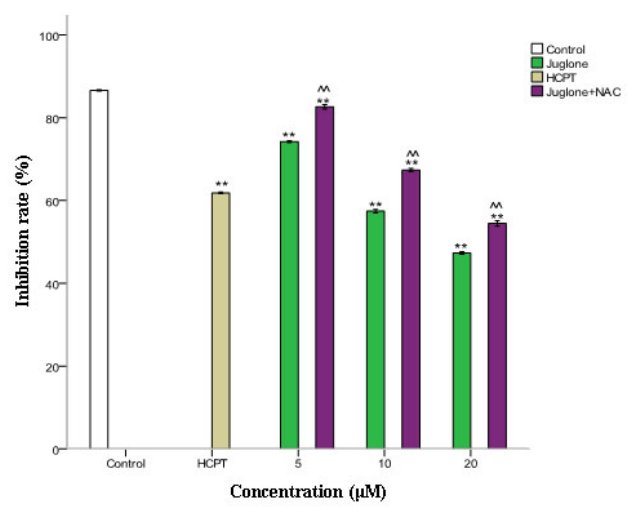

Figure 5. Effects of Juglone on cell mitochondria membrane potentials of MCF-7 cells. Result of mitochondria membrane changes. The corresponding histogram. Mitochondrial membrane potential of both Juglone group and juglone+NAC group was lower than control group, and that of juglone alone group was lower than juglone combined NAC group. ${ }^{* *}$ Compared with Control $\mathrm{P}<0.01 .{ }^{\wedge}$ Compared with matched doses of juglone $\mathrm{P}<0.01$.

\section{Effect of juglone on $\mathrm{Ca}^{2+}$ concentration of MCF-7 cells}

As shown in Figure 6, intracellular $\mathrm{Ca}^{2+}$ concentration in positive controls was significantly higher than in blank controls $(\mathrm{P}<0.01)$, and was significantly higher in juglonetreated cells than in the blank controls $(\mathrm{P}<0.01)$. The intracellular $\mathrm{Ca}^{2+}$ concentration also increased with increase of juglone concentration. $\mathrm{Ca}^{2+}$ concentration was significantly higher in NAC combined-treatment groups than in blank controls, but significantly lower than in the corresponding juglone-only groups $(\mathrm{P}<0.01)$.

\section{Effect of juglone on caspase 3 activity in MCF-7 cells}

As shown in Figure 7, juglone activated caspase 3 in a concentration-dependent manner. Caspase- 3 activity in HPCP group was significantly higher than in the control group, and was $12.12,28.79$, and $48.48 \%$ higher in cells treated with 5,10 , and $20 \mu \mathrm{M}$ juglone, respectively, than in the controls $(\mathrm{P}<0.01)$. Caspase-3 activity of cells in the NAC combinedtreatment groups was $4.55,18.18$, and $30.30 \%$ higher than the control cell values $(\mathrm{P}<0.01)$ and significantly lower than the values in cells treated with juglone only $(\mathrm{P}<0.01)$.

Genetics and Molecular Research 15 (3): gmr.15038785 

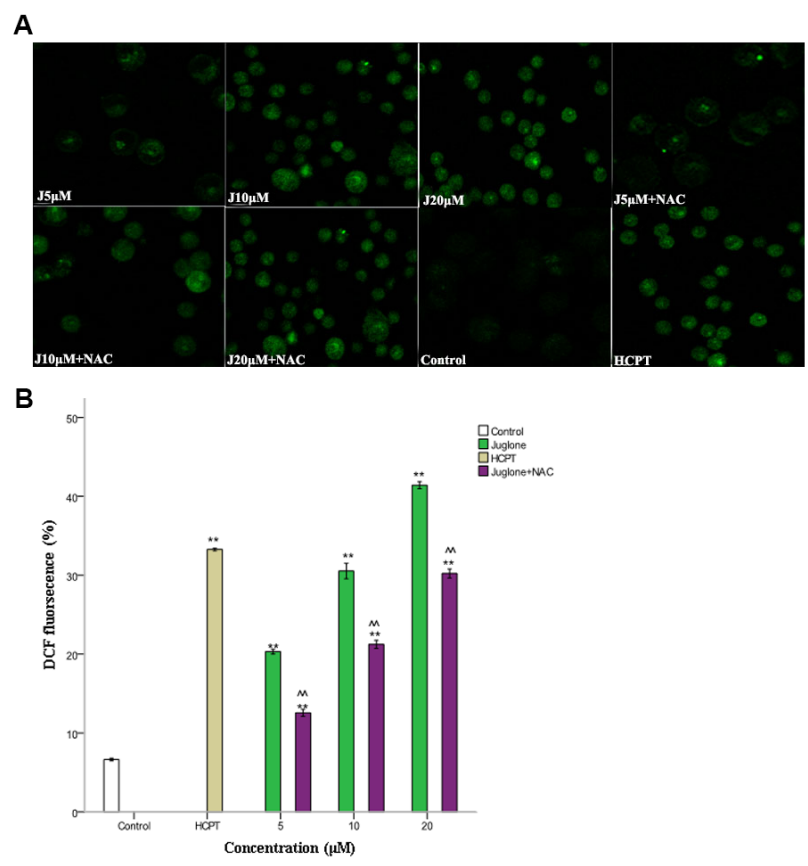

Figure 6. Effect of juglone on $\mathrm{Ca}^{2+}$ concentration of MCF-7 cells. Images showing the effect of juglone on intracellular $\mathrm{Ca} 2+$ concentration. The corresponding histogram. Mitochondrial membrane potential of both juglone group and juglone+NAC group was higher than control group. The membrane potential of the juglone group was higher than juglone+NAC group. ${ }^{* *}$ Compared with Control $\mathrm{P}<0.01 .{ }^{\wedge}$ Compared with matched doses of juglone $\mathrm{P}<0.01$.

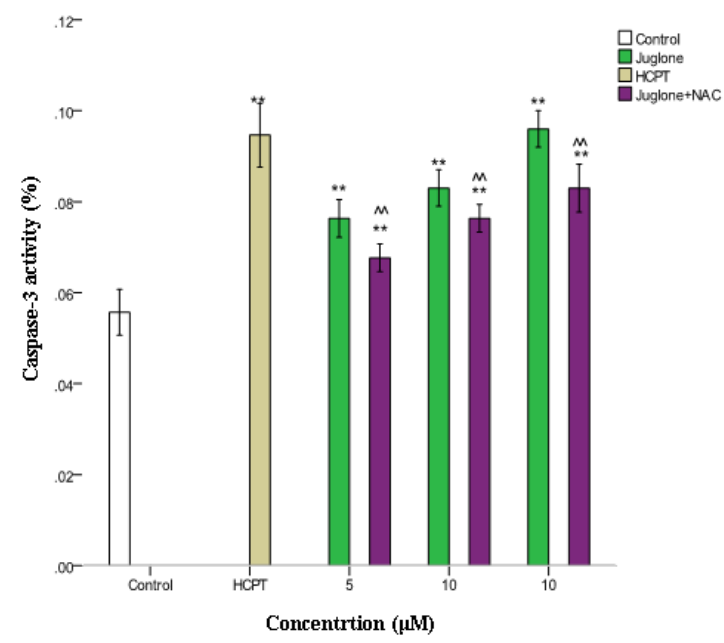

Figure 7. Effect of juglone on caspase 3 activity of MCF-7 cells The green column represents juglone group, the purple column represents juglone+NAC group, the $\mathrm{X}$ axis represents the concentration and the $\mathrm{Y}$ axis represents casepase-3 activity. Casepase-3 activity in all juglone alone group and juglone+NAC group was higher than control group and lower than HCPT group. With the concentration increased, the ROS level increased gradually in both group, while that of juglone alone group was higher than juglone combined NAC group. **Compared with Control $\mathrm{P}<0.01 .{ }^{\wedge}$ Compared with matched doses of juglone $\mathrm{P}<0.01$.

Genetics and Molecular Research 15 (3): gmr.15038785 


\section{Effect of juglone on the expression of Bcl-2 and Bax proteins in MCF-7cells}

As shown in Figure 8, the expression of Bcl-2 protein decreased significantly with increasing juglone concentration compared with the control cells $(\mathrm{P}<0.01)$, and expression was lower in cells treated with juglone alone than in cells treated with NAC plus juglone $(\mathrm{P}<$ 0.01). Bax protein expression was significantly higher after juglone exposure than in both the control cells and in cells given NAC with juglone $(\mathrm{P}<0.01)$. Protein expression was reported relative to the control and is shown in the histogram $(\mathrm{P}<0.01)$.
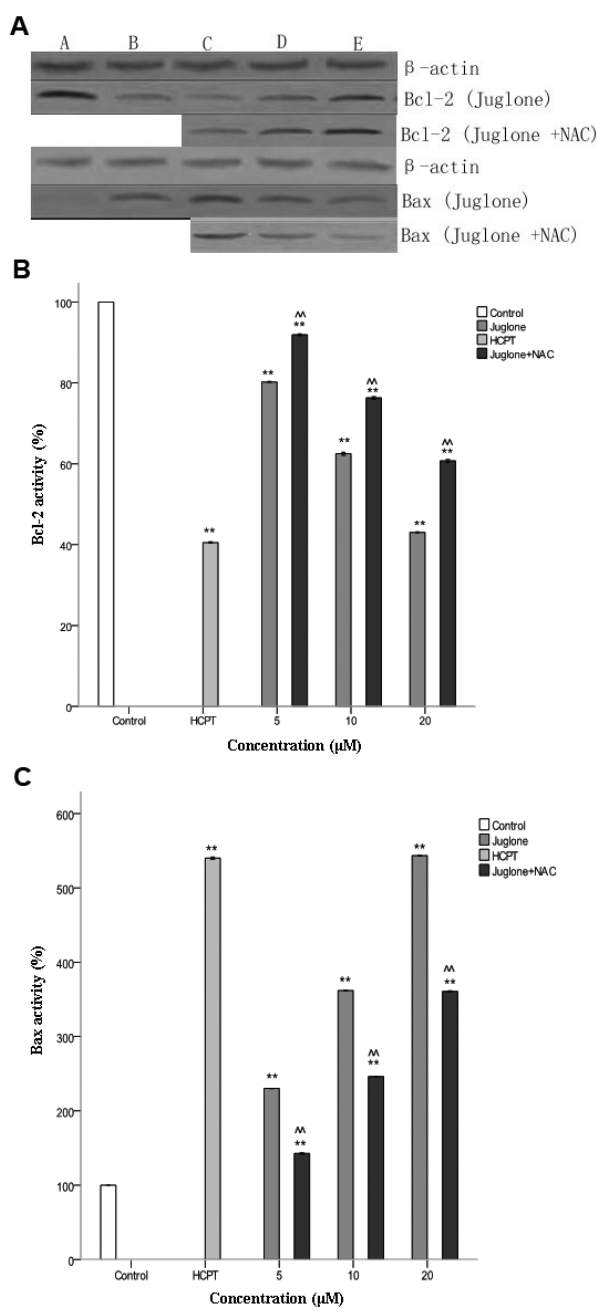

Figure 8. Effect of juglone on the expression of Bcl-2 and Bax proteins in MCF-7cells. Western blotting results for Bcl-2 and Bax expression. The corresponding histograms. The green column represents juglone group and the purple column represents juglone+NAC group. The Bcl-2 activity of juglone group was lower than corresponding juglone $+\mathrm{NAC}$ group. The Bax activity of juglone group was higher than corresponding juglone+NAC group. $* *$ Compared with Control $\mathrm{P}<0.01 .{ }^{\wedge}$ Compared with matched doses of juglone $\mathrm{P}<0.01$. 


\section{Effect of juglone on cytochrome $\mathrm{C}$ protein expression in MCF-7 cells}

The expression of cytochrome $\mathrm{C}$ protein was significantly higher in juglone treated cells $(5,10,20 \mathrm{mM})$ than in the control cells and in cells treated with NAC plus juglone (Figure 9). There was a positive correlation between cytochrome-c level and juglone concentration.

\section{A}
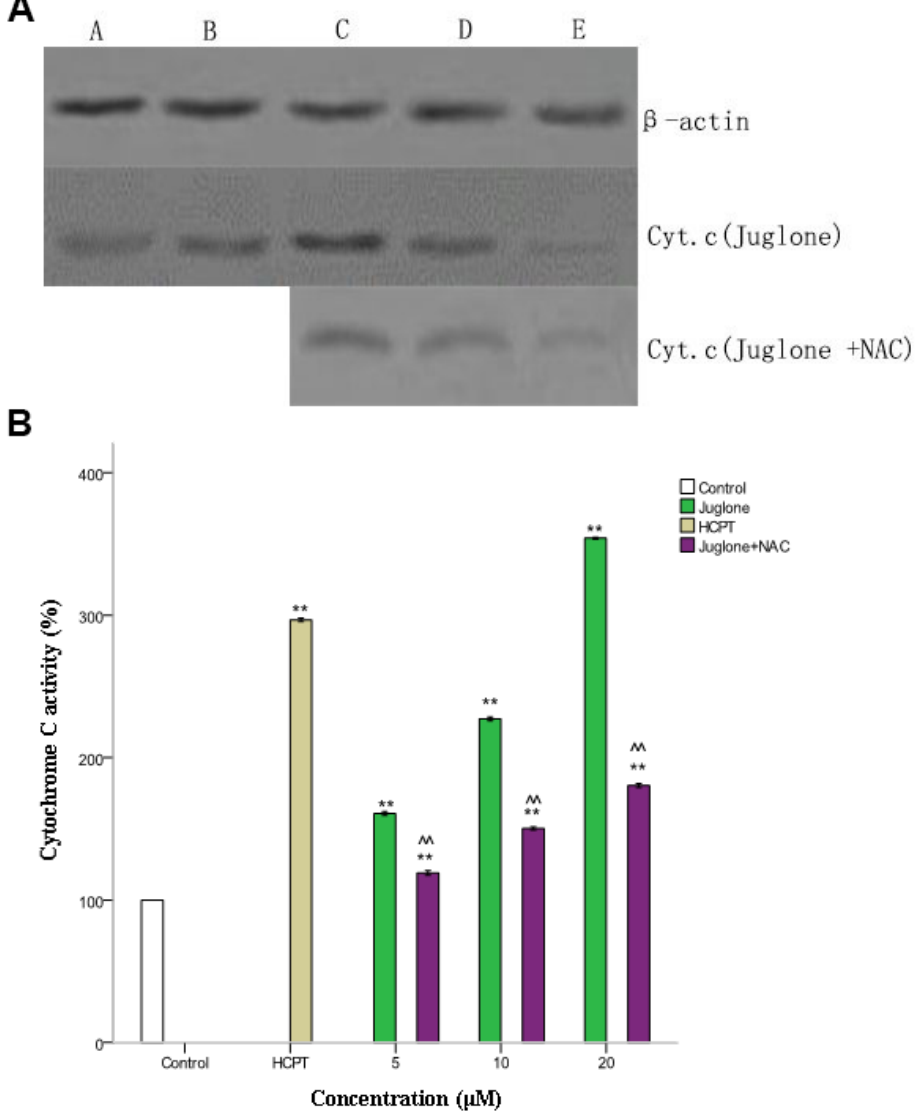

Figure 9. Effect of juglone on the expression of cytochrome C protein in MCF-7 cells. Western blotting results the corresponding histogram. The green column represents juglone group and the purple column represents juglone $+\mathrm{NAC}$ group. The cytochrome $\mathrm{C}$ activity of juglone group was higher than corresponding juglone $+\mathrm{NAC}$ group. **Compared with Control $\mathrm{P}<0.01$. ${ }^{\wedge}$ Compared with matched doses of juglone $\mathrm{P}<0.01$.

\section{DISCUSSION}

To our knowledge, this is the first report regarding the effect of juglone on MCF7 cells. The MTT assay showed that juglone suppressed the proliferation of MCF-7 cells, and that NAC antagonized that effect. Giemsa and fluorescence staining showed that the morphology of juglone-exposed MCF-7 cells was consistent with apoptosis.

In addition to the morphological evidence, flow cytometry showed that apoptosis in each treatment group reached a peak at $72 \mathrm{~h}$ after juglone treatment, and that the increase 
in apoptosis rate was accompanied by increased density, which is consistent with previous reports (Ji et al., 2011). In the presence of NAC, juglone-induced apoptosis rate decreased significantly. Previous research has shown that juglone is converted into a semiquinone radical via single electron oxidoreduction (Inbaraj and Chignell, 2004). The semiquinone radical can rapidly convert molecular oxygen into a superoxide anion $\left(\mathrm{O}_{2}^{-}\right)$, which then produces $\mathrm{H}_{2} \mathrm{O}_{2}$ enzymatically; the latter can be changed into a highly active hydroxyl free radical $\left(\mathrm{OH}^{*}\right)$ via $^{2}$ the Fenton reaction. The species $\mathrm{O}_{2}^{-}, \mathrm{H}_{2} \mathrm{O}_{2}$, and $\mathrm{OH}^{-}$are all ROS (Bolton et al., 2000; Klaus et al., 2010). ROS can either regulate the physiological activity of cells, or cause oxidative damage to molecules and cell organelles (Srinivas et al., 2004; Gomathinayagam et al., 2008). In the present study, flow cytometry showed that juglone increased the levels of ROS in MCF-7 cells, in agreement with previous findings (Inbaraj and Chignell, 2004), but that this effect was reduced in the presence of NAC. Increased ROS levels likely interfere with the functioning of the mitochondrial electron transport chain, and decrease mitochondrial transmembrane potential by reducing the oxidation state of the mitochondrial inner membrane and by damaging mitochondrial DNA and several key proteins (Hall et al., 2015).

Decrease of mitochondrial electron transport is due, in part, to oxidative injury and change in intracellular $\mathrm{Ca}^{2+}$ concentration (Kolupaev et al., 2014). In the early phase of apoptosis, mitochondrial $\mathrm{Ca}^{2+}$ release leads to an increase in intracellular $\mathrm{Ca}^{2+}$ levels (Akopova et al., 2013). Sustained high levels of ROS likely promote destruction of organelle and cell membranes, as well as redistribution and continuous intracellular accumulation of $\mathrm{Ca}^{2+}$ ( $\mathrm{Li}$ et al., 2014). Thus, the generation of ROS and the increase in intracellular $\mathrm{Ca}^{2+}$ concentration are interconnected during the progression of apoptosis. The results of laser scanning confocal microscopy demonstrated that juglone increased the $\mathrm{Ca}^{2+}$ concentration in MCF-7 cells, while NAC antagonized this effect. Juglone also reduced Bcl-2 expression, increased Bax expression, and released cytochrome-c from the mitochondria into the cytoplasm; NAC antagonized these effects as well. The Bcl-2 protein family includes factors that regulate apoptosis (Zimmermann et al., 2007) and act intracellularly by changing the mitochondrial membrane potential and the permeability of mitochondrial membranes, thus affecting the release of proteins that recruit the apoptotic machinery (Chakraborty et al., 2014).

Bax promotes the opening of mitochondrial permeability transition pores (PTPs) to induce apoptosis, while Bcl-2 inhibits the opening of PTPs and prevents apoptosis (Liu et al., 2013; Al-Fatlawi et al., 2014). The decrease in Bcl-2 expression and increase in Bax expression likely promotes the opening of mitochondrial PTPs, inflow of $\mathrm{Ca}^{2+}$ into the mitochondrial matrix, imbalance of osmotic pressure, and decrease in mitochondrial membrane potential (Cheng et al., 2011). The opening of mitochondrial PTPs leads to relative hypertonicity of the mitochondria, expansion of the mitochondrial matrix, disruption of the adventitia, and release of apoptotic proteins such as cytochrome $\mathrm{C}$, a component of the respiratory chain (Bonora and Pinton, 2014). When mitochondrial PTPs open and mitochondria are injured, cytochrome $\mathrm{C}$ flow out into the cytoplasm (Huang et al., 2001), further promoting apoptosis by recruitment of caspases (Naoi et al., 2013).

Overall, the results obtained in our study showed that juglone inhibited the proliferation of MCF-7 human breast cancer cells and promoted apoptosis by elevating ROS levels, reducing Bcl-2 expression, increasing Bax expression, decreasing mitochondrial membrane potential, increasing intracellular $\mathrm{Ca}^{2+}$ concentrations, promoting the rupture of the outer mitochondrial membrane, releasing cytochrome $\mathrm{C}$, and activating caspase- 3 . These results provide valuable new insight into the mechanism of juglone-induced apoptosis, with applications in the treatment of breast cancer.

Genetics and Molecular Research 15 (3): gmr.15038785 


\section{Conflicts of interest}

There authors declare no conflict of interest.

\section{ACKNOWLEDGMENTS}

Research supported by the Natural Science Foundation of Heilongjiang Province (\#D201229) and the National Natural Science Foundation of China (\#81274067).

\section{REFERENCES}

Akopova OV, Nosar' VI, Man'kovskaia IN and Sagach VF (2013). The effect of Ca(2+)-induced opening of cyclosporinesensitive pore on the oxygen consumption and functional state of rat liver mitochondria. Ukr Biokhim Zh (1999) 85: 37-49.

Al-Fatlawi AA, Al-Fatlawi AA, Irshad M, Zafaryab M, et al. (2014). Rice bran phytic acid induced apoptosis through regulation of $\mathrm{Bcl}-2 / \mathrm{Bax}$ and 533 genes in $\mathrm{HepG} 2$ human hepatocellular carcinoma cells. Asian Pac. J. Cancer Prev. 15: 3731-3736. http://dx.doi.org/10.7314/APJCP.2014.15.8.3731

Bolton JL, Trush MA, Penning TM, Dryhurst G, et al. (2000). Role of quinones in toxicology. Chem. Res. Toxicol. 13: 135-160. http://dx.doi.org/10.1021/tx9902082

Bonora M and Pinton P (2014). The mitochondrial permeability transition pore and cancer: molecular mechanisms involved in cell death. Front. Oncol. 4: 302. http://dx.doi.org/10.3389/fonc.2014.00302

Chakraborty S, Mazumdar M, Mukherjee S, Bhattacharjee P, et al. (2014). Restoration of p53/miR-34a regulatory axis decreases survival advantage and ensures Bax-dependent apoptosis of non-small cell lung carcinoma cells. FEBS Lett. 588: 549-559. http://dx.doi.org/10.1016/j.febslet.2013.11.040

Cheng Y, Gulbins E and Siemen D (2011). Activation of the permeability transition pore by Bax via inhibition of the mitochondrial BK channel. Cell Physiol. Biochem. 27: 191-200.

Gomathinayagam R, Sowmyalakshmi S, Mardhatillah F, Kumar R, et al. (2008). Anticancer mechanism of plumbagin, a natural compound, on non-small cell lung cancer cells. Anticancer Res. 28 (2A): 785-792.

Hall SR, Blundon HL, Ladda MA, Robertson AW, et al. (2015). Jadomycin breast cancer cytotoxicity is mediated by a copper-dependent, reactive oxygen species-inducing mechanism. Pharmacol. Res. Perspect. 3: e00110. http://dx.doi. org/10.1002/prp2.110

Huang X, Zhai D and Huang Y (2001). Dependence of permeability transition pore opening and cytochrome C release from mitochondria on mitochondria energetic status. Mol. Cell. Biochem. 224: 1-7. http://dx.doi. org/10.1023/A:1011990300114

Inbaraj JJ and Chignell CF (2004). Cytotoxic action of juglone and plumbagin: a mechanistic study using HaCaT keratinocytes. Chem. Res. Toxicol. 17: 55-62. http://dx.doi.org/10.1021/tx034132s

Jaradat NA, Shawahna R, Eid AM, Al-Ramahi R, et al. (2016). Herbal remedies use by breast cancer patients in the West Bank of Palestine. J. Ethnopharmacol. 178: 1-8. http://dx.doi.org/10.1016/j.jep.2015.11.050

Ji YB, Qu ZY and Zou X (2011). Juglone-induced apoptosis in human gastric cancer SGC-7901 cells via the mitochondrial pathway. Exp. Toxicol. Pathol. 63: 69-78.

Kamei H, Koide T, Kojima T, Hashimoto Y, et al. (1998). Inhibition of cell growth in culture by quinones. Cancer Biother. Radiopharm. 13: 185-188. http://dx.doi.org/10.1089/cbr.1998.13.185

Klaus V, Hartmann T, Gambini J, Graf P, et al. (2010). 1,4-Naphthoquinones as inducers of oxidative damage and stress signaling in HaCaT human keratinocytes. Arch. Biochem. Biophys. 496: 93-100. http://dx.doi.org/10.1016/j. abb.2010.02.002

Kolupaev IuE, Vaĭner AA, Iastreb TO, Obozny̌ AI, et al. (2014). The role of reactive oxygen species and calcium ions in the implementation of the stress-protective effect of brassinosteroids on plant cells. Prikl. Biokhim. Mikrobiol. 50: 593-598. http://dx.doi.org/10.7868/S0555109914060075

Li L, Tan H, Gu Z, Liu Z, et al. (2014). Heat stress induces apoptosis through a $\mathrm{Ca}^{2+}$-mediated mitochondrial apoptotic pathway in human umbilical vein endothelial cells. PLoS One 9: e111083. http://dx.doi.org/10.1371/journal. pone. 0111083

Liu G, Wang T, Wang T, Song J, et al. (2013). Effects of apoptosis-related proteins caspase-3, Bax and Bcl-2 on cerebral ischemia rats. Biomed. Rep. 1: 861-867.

Genetics and Molecular Research 15 (3): gmr.15038785 
Naoi M, Maruyama W, Yi H.(2013). Rasagiline prevents apoptosis induced by PK11195, a ligand of the outer membrane translocator protein $(18 \mathrm{kDa})$, in SH-SY5Y cells through suppression of cytochrome c release from mitochondria. $J$. Neural Transm. 120: 1539-1551.

Segura-Aguilar J, Jönsson K, Tidefelt U and Paul C (1992). The cytotoxic effects of 5-OH-1,4-naphthoquinone and 5,8-diOH-1,4-naphthoquinone on doxorubicin-resistant human leukemia cells (HL-60). Leuk. Res. 16: 631-637. http://dx.doi.org/10.1016/0145-2126(92)90013-W

Srinivas P, Gopinath G, Banerji A, Dinakar A, et al. (2004). Plumbagin induces reactive oxygen species, which mediate apoptosis in human cervical cancer cells. Mol. Carcinog. 40: 201-211. http://dx.doi.org/10.1002/mc.20031

Zimmermann AK, Loucks FA, Schroeder EK, Bouchard RJ, et al. (2007). Glutathione binding to the Bcl-2 homology-3 domain groove: a molecular basis for Bcl-2 antioxidant function at mitochondria. J. Biol. Chem. 282: 29296-29304. http://dx.doi.org/10.1074/jbc.M702853200

Genetics and Molecular Research 15 (3): gmr.15038785 